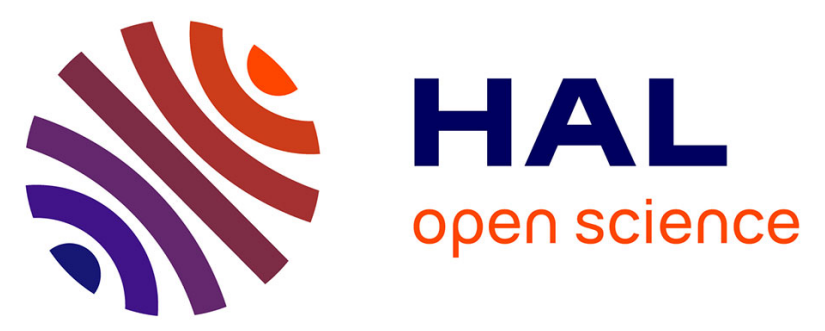

\title{
Sodium-channel blocker challenge in the familial screening of Brugada syndrome: safety and predictors of positivity
}

\author{
Dylan Therasse, Frédéric Sacher, Bertrand Petit, Dominique Babuty, Philippe
} Mabo, Raphael Martins, Laurence Jesel, Philippe Maury, Jean Luc Pasquie, Jacques Mansourati, et al.

\section{To cite this version:}

Dylan Therasse, Frédéric Sacher, Bertrand Petit, Dominique Babuty, Philippe Mabo, et al.. Sodiumchannel blocker challenge in the familial screening of Brugada syndrome: safety and predictors of positivity. Heart Rhythm, 2017, 14 (10), pp.1442-1448. 10.1016/j.hrthm.2017.06.031 . hal-01650124

HAL Id: hal-01650124

https://hal-univ-rennes1.archives-ouvertes.fr/hal-01650124

Submitted on 28 Nov 2017

HAL is a multi-disciplinary open access archive for the deposit and dissemination of scientific research documents, whether they are published or not. The documents may come from teaching and research institutions in France or abroad, or from public or private research centers.
L'archive ouverte pluridisciplinaire HAL, est destinée au dépôt et à la diffusion de documents scientifiques de niveau recherche, publiés ou non, émanant des établissements d'enseignement et de recherche français ou étrangers, des laboratoires publics ou privés. 
Sodium-channel blocker challenge in the familial screening of Brugada syndrome: safety and predictors of positivity.

3 Dylan THERASSE ${ }^{1}$, MD, Frederic SACHER ${ }^{2}, \mathrm{MD}$, Bertrand PETIT $^{3}, \mathrm{MD}$, Dominique 4 BABUTY ${ }^{4}, \mathrm{MD}, \mathrm{PhD}$, Philippe $\mathrm{MABO}^{5}, \mathrm{MD}, \mathrm{PhD}$, Raphael MARTINS ${ }^{5}, \mathrm{MD}, \mathrm{PhD}$, 5 Laurence JESEL ${ }^{6}, \mathrm{MD}$, Philippe MAURY ${ }^{7}, \mathrm{MD}, \mathrm{PhD}$, Jean Luc PASQUIE ${ }^{8}, \mathrm{MD}, \mathrm{PhD}$, 6 Jacques MANSOURATI ${ }^{9}, \mathrm{MD}, \mathrm{PhD}$, Jean Marc DUPUIS ${ }^{10}$, MD, Florence KYNDT ${ }^{1,}{ }^{11}$, 7 PharmaD, PhD, Aurélie THOLLET ${ }^{1}$, PharmaD, PhD, Beatrice GUYOMARCH ${ }^{1}$, Julien 8 BARC $^{12}$, PhD, Jean Jacques SCHOTT ${ }^{1}$, PhD, Herve LE MAREC $^{1}$, MD, PhD, Richard $9 \mathrm{REDON}^{1}, \mathrm{PhD}$, Vincent PROBST ${ }^{1}, \mathrm{MD}, \mathrm{PhD}$, Jean-Baptiste GOURRAUD ${ }^{1}, \mathrm{MD}, \mathrm{PhD}$.

${ }^{1}$ l'institut du thorax, INSERM, CNRS, UNIV Nantes, CHU Nantes, Nantes, France; ${ }^{2}$ CHU

Bordeaux, Hôpital cardiologique, Bordeaux, France; ${ }^{3}$ CHR La Réunion, Service de Cardiologie, Saint Pierre, France; ${ }^{4}$ CHU Tours, Service de cardiologie, Tours, France; ${ }^{5} \mathrm{CHU}$ Rennes, Service de cardiologie, Rennes, France; ${ }^{6}$ CHU Strasbourg, Service de cardiologie, 14 Strasbourg, France; ${ }^{7}$ CHU Toulouse, Service de cardiologie, Toulouse, France; ${ }^{8} \mathrm{CHU}$ Montpellier, Service de cardiologie, Montpellier, France; ${ }^{9}$ CHU Brest, Service de cardiologie, Brest, France; ${ }^{10} \mathrm{CHU}$ Angers, Service de cardiologie, Angers, France; ${ }^{11} \mathrm{CHU}$ Nantes, Service de Génétique Médicale, Nantes, F-44000 France ; ${ }^{12}$ l'institut du thorax, INSERM, CNRS, UNIV Nantes, Nantes, France.

Short title: Sodium channel blockers test in familial Brugada syndrome

Corresponding author: Jean-baptiste Gourraud, Service de cardiologie, CHU de Nantes, Hôpital Nord Laennec, boulevard Jacques Monod, 44093 Nantes cedex, France; tel: +33-240165-009; fax: +33-240-165-024 ; e-mail: jeanbaptiste.gourraud@chu-nantes.fr

23 Conflicts of Interest statement: The authors have no conflicts of interest nor financial relationships relevant to this article to disclose. 
$1 \quad$ ABSTRACT

2 Background: Sodium channel blocker challenge (SCBC) is frequently performed to unmask

3 Brugada syndrome $(\mathrm{BrS})$.

4 Objectives: We aim to identify, predictors of positivity and complications of SCBC, in the

5 setting of familial screening.

6 Methods: All consecutive patients from 2000 to 2014 who benefit from a SBC and belong to

7 a family with at least 2 subjects affected by the syndrome were enrolled and followed

8 prospectively. Data were reviewed by 2 physicians blinded to the clinical and genetic status.

9 Results: Among 672 SCBC performed in 137 families, 337(50\%) were positive. Multivariate 10 analysis identified ajmaline (OR 2.98 (1.65-4.91), a significant $\mathrm{S}$ wave in DII (OR=3.11 $11(2.12-4.58), \mathrm{DIII}(\mathrm{OR}=2.75(1.78-4.25)$ or V5 lead $(\mathrm{OR}=3.71(2.54-5.44)$, as predictors of a 12 positive SCBC $(P<0.0001)$. Eleven $(1.6 \%)$ patients presented complications $(10$ ventricular arrhythmia, 1 atrial flutter) but no deaths occurred. A familial history of complications (OR = 41 [10; 203]; $P<0.0001)$, young age $(P=0.04)$ and decreased conduction ECG parameters at baseline $(\mathrm{p}=0.04)$ were predictors of complication. QRS enlargement during SCBC was not associated with complications.

During a median follow-up of 106 [54-143] months, 11 life-threatening arrhythmia occurred.

Conclusions: SCBC in the screening of familial Brs is safe. The risk of complication is considerably increased in case of familial history of complicated SCBC, in very young patients and in the presence of decreased ECG conduction parameters. However, QRS enlargement during the test is not directly related to complications and should not be used to prematurely stop the test unless leading to false negative results.

24 Key words: Brugada syndrome; Sodium Channel Blockers Challenge; Ajmaline; Flecainide; 


\section{Introduction}

2

Brugada syndrome $(\mathrm{BrS})$ is responsible for sudden cardiac death $(\mathrm{SCD})$ due to

4 ventricular fibrillation (VF) which typically occurs at rest and could be the first manifestation

5 of the disease ${ }^{1}$. Diagnosis is based on a specific ECG pattern - type 1 ST segment elevation in

6 the right precordial leads as defined in the recent guidelines ${ }^{2}$. Owing to the variability of this

7 ECG pattern, its prevalence in the general population remains unclear but has been estimated

8 to range between $0.05 \%$ and $0.2 \%^{3-5}$. In subjects without spontaneous type 1 ECG aspect,

9 sodium channel blocker challenge (SCBC) is commonly used to unmask the ECG pattern ${ }^{2,6}$.

10 Ajmaline and flecainide are the most commonly used drugs while Procainamide is considered

11 as less efficient ${ }^{6}$.

12 While this test is widely used, its safety remains a matter to debate ${ }^{7-11}$. Indeed, last

13 guidelines consider as a stopping criteria, a QRS enlargement of more than $30 \%^{2}$.

14 Challenging this criteria, Batchvarov et al have suggested that it can lead to underdiagnose

15 BrS while the risk of complications in this situation appears to be low $^{7}$.

16 The aim of this study was to evaluate, aside from QRS enlargement stopping criteria,

17 the safety and predictors of a positive SCBC, during familial screening of Brs. 
1 Methods

\section{Study Population and design}

All consecutive patients undergoing SCBC during familial screening of Brs, in 10

4 French university hospitals from 2000 to 2014, were included. This study was conducted

5 according to European guidelines for clinical and genetic research. Informed written consent

6 was obtained from each patient who agreed to participate in the clinical and genetic study.

Except for QRS enlargement stopping criteria, SCBCs were performed according to

8 the second consensus conference (Ajmaline: $1 \mathrm{mg} / \mathrm{kg}$; Flecainide: $2 \mathrm{mg} / \mathrm{kg}$ ) ${ }^{6}$. Complications

9 were defined as occurrence of ventricular arrhythmias (VF) and sustained or non-sustained 10 ventricular tachycardia (VT), atrial arrhythmias or atrioventricular block.

The diagnosis of $\mathrm{BrS}$ was based on 2013 criteria $^{2}$ with the presence of a typical type 1

\section{ECG data}

Two physicians blinded to the clinical and genetic status reviewed baseline ECG, first diagnosis ECG during SCBC or ECG at the end of the test in case of negative test.

P wave, PQ interval, QRS, QT peak, QTend, QTc duration (corrected by Bazett's formula) and Tpeak-Tend interval (TPE, time interval between the peak and the end of the T wave) were measured in V1. Additional parameters were measured in DII (terminal S wave 
1 duration and amplitude), DIII (terminal $\mathrm{S}$ wave duration and amplitude), V5 (terminal $\mathrm{S}$ wave

2 duration and amplitude) and aVR (terminal $\mathrm{R}$ wave duration and amplitude).

4 Health, Bethesda, Maryland, http://rsb. info.nih.gov/ij). mutations according to the genetic status of the proband.

Genomic DNA was extracted from peripheral blood leukocytes using standard protocols. All 28 exons of SCN5A were amplified by polymerase chain reaction (PCR) utilizing intronic primers. PCR products were screened for SCN5A mutations using denaturing high performance liquid chromatography (dHPLC)-DNA sequencing or High Resolution Melting (HRM). The description of mutations is based on cDNA reference sequence GenBank NM_198056.

This study was conducted according to European guidelines for clinical and genetic research. Institutional ethical committees approved clinical and genetic database. Informed written consent was obtained from each patient who agreed to participate in the clinical and genetic study.

\section{Statistical Analysis}

Data were analysed with the SPSS and SAS packages (SPSS Inc version 23,0, Chicago, Ill; SAS Institute Inc version 9,4, Cary, NC). quartile), as appropriate. Continuous variables were analysed by Student's unpaired $t$-test or the Wilcoxon test, as appropriate. The $\chi 2$ test and Fisher's exact test were used for comparison of categorical variables. associated with positive tests. 


\section{ACCEPTED MANUSCRIPT}

1

All tests were 2 tailed and a $P$ value under 0.05 was considered as statistically

\section{2 significant.}

3

4 
$1 \underline{\text { Results }}$

2 Population

The study population consist of 672 consecutive patients from 137 families (median

4 age $40 \pm 17$ years). Three hundred and twenty-eight patients were male (49\%). Three hundred

5 and thirty-seven patients (50\%) presented a positive SCBC with an induced type 1 ECG

6 pattern. The molecule used was ajmaline in 497 (74\%) and flecainide in 175 (26\%) SCBC.

7 SCN5A mutation was identified in 43/136 (31\%) probands and in 120/268 (45\%) of their

8 relatives. Population characteristics are summarized in Table 1.

\section{Characteristics of positive $\mathrm{SCBC}$}

Among the 672 SCBC, a positive result was associated with age (41+/- 16 vs $36+/-17$

11 $\mathrm{y} ; \mathrm{p}=0.004)$, the presence of a SCN5A mutation in the family (93 (79\%) vs $27(28 \%)$; $\mathrm{p}<0.001)$ and the use of ajmaline $(272(54 \%)$ of positive SCBC vs $65(37 \%)$ for flecainide; $\mathrm{p}<0.001$ ) (figure 1).

Patients with a positive SCBC additionally presented at baseline a longer $\mathrm{P}$ wave $(68 \pm$ $19 \mathrm{~ms}$ vs $62 \pm 17 \mathrm{~ms} ; P<0.001)$, PR $(156 \pm 31 \mathrm{~ms}$ vs $146 \pm 27 \mathrm{~ms} ; P<0.001)$ and QTc interval (407 $\pm 39 \mathrm{~ms}$ vs $394 \pm 36 \mathrm{~ms} ; \mathrm{P}<0.001)$ in V1 lead and a longer QRS interval $(92 \pm$ $19 \mathrm{~ms}$ vs $82 \pm 16 \mathrm{~ms} ; P<0.001)$ in DII lead. Both duration and amplitude of the terminal $\mathrm{S}$ wave in DII, DIII and V5 leads and the terminal R wave in aVR were also associated with a positive SCBC $(P<0.0001)$. Similar results were observed at the end of the SCBC (Table 2). In multivariate analysis, the drug used (ajmaline vs flecainide) was the best predictor of a positive SCBC (OR $2.98(1.65-4.91) ; P<0.0001)$. A significant S wave (e.g., amplitude> $1 \mathrm{mV}$ and duration $>40 \mathrm{~ms})$ in DII $(\mathrm{OR}=3.11(2.12-4.58), P<0.0001, \mathrm{DIII}(\mathrm{OR}=2.75(1.78-$ 4.25), $P<0.0001)$ and V5 lead $(\mathrm{OR}=3.71(2.54-5.44), P<0.0001)$ or a significant terminal $\mathrm{R}$ wave in aVR $(\mathrm{OR}=2.22(1.51-3.26), P<0.0001)$ were also associated with a positive SCBC (Figure 1). 
1

2

3

4

\section{Complications}

Among the 672 SCBC performed, complications occurred in 11 (1.6\%) including 9 sustained VT, one VF and one atrial flutter. Four of these patients required external DC shock. There were neither high-grade conduction disorders, nor deaths caused by SCBC. Three families presented complications during SCBC in several (2 to 3) family members. SCN5A variant segregating with the phenotype has been identified in those three families. The (c.2254G>A) has been previously described as a mutation. ${ }^{12,13}$ The two others (c.2998C >T and c.5417_5420del) are frameshift or non-sense variant whose one has been previously described ${ }^{14}$.

The main clinical risk factor for complications was familial history of complicated SCBC $(\mathrm{OR}=41$ [10; 203]; $P<0.0001)$ and younger age (median age $21 \pm 18 \mathrm{v} 42 \pm 16$ years; $P=0.04)$. There was a non-significant trend to a higher risk of complications with the use of ajmaline (11 complications /497 SCBCs for ajmaline vs 0/175 for flecainide; $P=0.07$ ).

Complications were also associated with a longer $\mathrm{P}$ wave $(114 \pm 16$ vs $92 \pm 18 \mathrm{~ms} ; P$ $=0.004)$ and PR interval $(192 \pm 27 \mathrm{~ms}$ vs $162 \pm 28 \mathrm{~ms} ; P=0.004)$ at baseline. The terminal S wave in lead DII ( $65 \pm 25 \mathrm{~ms}$ vs $32 \pm 23 \mathrm{~ms} ; P<0.0001)$, DIII $(57 \pm 30 \mathrm{~ms}$ vs $25 \pm 27 \mathrm{~ms} ; P$ $<0.0001)$ and the terminal $\mathrm{R}$ wave in aVR $(50 \pm 16 \mathrm{~ms}$ vs $30 \pm 21 \mathrm{~ms} ; P<0.0001)$ duration were also significantly larger in complicated SCBC.

QRS duration during SCBC was not associated with complications $(133 \pm 21 \mathrm{~ms}$ vs $134 \pm 35 \mathrm{~ms} ; \mathrm{P}=0.9$ ) (figure 2). However, among the 11 patients with complications, 6 (54\%) does not achieve the drug challenge leading to decrease the median dose of sodium channel blocker to $0.25(0.2-0.5) \mathrm{mg} / \mathrm{kg}$. Additionally, median QRS enlargement during the test trend to be higher in the presence of complication $(133 \%+-22$ vs $127 \%+-31 ; \mathrm{p}=0.06)$. Fifty-seven percent of patient with positive tests and 39\% of patients with negative tests had a QRS enlargement higher than $30 \%$ in DII lead. 
$1 \quad$ Clinical Follow-up

2

After a median follow-up of 106 [54-143] months, 11 patients (73\% male; mean age:

$338 \pm 18$ y) experienced life-threatening arrhythmia including 1 SCD, 1 aborted SCD and 9

4 appropriate shocks. These nine patients who experienced appropriated shock had positive

5 SCBC.

6

7 
1

2

3

4

\section{$\underline{\text { Discussion }}$}

SCBC is the corner stone of Brs screening as it allows unmasking the diagnostic Brugada ECG pattern particulary during familial screening. Considering the doubt about SCBC safety and a low risk of arrhythmia in asymptomatic relatives with undiagnosed baseline ECG, some argues this familial screening should be restricted ${ }^{15}$. However, diagnosis in such patients can allow to introduce general lifestyle changes preventing arrhythmia occurrence and to carry on with the familial screening in descendant, which can present a higher risk of arrhythmia ${ }^{16}$.

Overall, our study demonstrated that SCBC is safe. The complication rate was only $1.6 \%$, confirming the safety of this test when performed in an appropriate environment ${ }^{8}$. We identified that family history of adverse events during the SCBC represents the stronger risk factor for the occurrence of arrhythmia during the test. Indeed, $63 \%$ of the complications (7/11) in our study involved 3 out of the 137 families studied. This data suggests that these families have an increased susceptibility to the occurrence of complications probably due to a particular genotype. Of note, a SCN5A mutation was found in these three families. Those families presented with segregation of a SCN5A variant, whose one has been previously described as a mutation ${ }^{12,13}$ and the two others are frameshift or non sense mutation that may lead to a decreased $\mathrm{Na}$ current and an increased effect of sodium channel blockers ${ }^{14}$. However, the phenotype we observed has never been described in previous studies of patients carrying the same mutation.

Patients with complications were also younger (median age: $21 \pm 18$ years). As recently described by Conte ${ }^{17}$, the risk of complications is increased in children. In our study, 8 patients were under 16 years of age at the time of the SCBC and $3(37.5 \%)$ presented a complication during the test that is from far higher than in the rest of the population. There is currently no clear explanation for this increased rate. In children, because of the absence of 
1 fibrosis of the his bundle and its branches, there is a good security factor allowing a normal or

2 subnormal propagation of the cardiac influx even in case of decrease of the sodium current,

3 such with SCN5A mutation ${ }^{18}$. This may explain the rarity of the Brugada syndrome in

4 children $^{19,20}$. However, although Brs is relatively rare in children, it appears to be associated

5 with an increased rate of conduction disturbance at baseline ${ }^{17,19-21}$. Then, SCN5A mutation

6 are from far more frequent in children with Brs than in adult ${ }^{20}$ that confirm the importance of

7 a decreased sodium current to unmask the Brugada syndrome in children. This suggests that

8 the presence of conduction abnormalities (even minor) in children is in fact in relation with a

9 strong decrease of the ability of the cardiac influx to propagate into the conduction tissue. In

10 this situation, the addition of a sodium cardiac blocker could lead to a dramatic decrease of

11 the conduction and then to severe complications. This is in line with the fact that, in our study,

12 conduction disturbance at baseline is associated with complication occurrence. Notably, the 13 presence of a terminal S wave in DII, DIII and V5 or a terminal R wave in aVR, which can 14 represent enhanced conduction delay in the right ventricular outflow tract (RVOT) ${ }^{22}$, depict 15 patients at higher risk of complications during the test.

QRS enlargement during the test was previously related to a high risk of 17 complications $^{6}$. As previously suggested by Batchvarov ${ }^{7}$, our study demonstrates that a significant number of patients have an enlargement of the QRS over $30 \%$ before the end of the test. In fact, $57 \%$ of patient with positive tests had a QRS enlargement higher than $30 \%$ meaning that if we had strictly followed the guidelines, the sensitivity of the test will have

21 been dramatically decreased while the risk of complications in this situation appears to be 22 low. Then, our results suggest changing the guidelines, as stopping prematurely the test for 23 QRS enlargement of more than $30 \%$ will lead to an unacceptable number of patients 24 undiagnosed without significantly decreasing the risk of complications. However, as 25 demonstrated in several case reports ${ }^{9,23,24}$, management of such QRS enlargement could 
1 require specific attention. Indeed, in the complicated group, the QRS enlargement appears to

2 be faster despite a lower dosage of SCN5A channel blockers. Although we are not able to

3 identify stopping criteria according to the QRS enlargement kinetic, a fast enlargement during

4 the test may sensitize the physician about the risk of complication. As a consequence, SCBC

$5 \quad$ should always be performed in experienced center.

6

\section{$7 \quad$ ECG criteria to detect patients at high risk of a positive test} essential both in the diagnosis and prognosis of BS patients.

$\underline{\text { Study limitations: }}$ Brugada electrocardiograms ${ }^{29}$.

We demonstrated that significant $\mathrm{S}$ wave in inferolateral leads and terminal $\mathrm{R}$ wave in aVR lead at baseline were associated with a positive response to SCBC. These results confirm previous study ${ }^{25}$ and can help to select patients who need the test to confirm the diagnosis of BrS. It also provides interesting findings in $\mathrm{BrS}$ pathogenesis. The third vector of cardiac depolarization, generating both such wave exhibits the depolarization of basal myocardium and in particular, the right ventricular outflow tract $(\mathrm{RVOT})^{22,26}$. Baseline conduction disturbances, especially axial deviation with prominent $S$ wave in inferior or lateral leads, highlight the role of conduction delay in the RVOT $^{27,28}$. This was recently emphasized by Calò who suggests the prognostic value of RVOT conduction delay using S wave in DI lead ${ }^{22}$. Our results reinforce the importance of conduction disturbance in the RVOT that appear to be

This study was a retrospective and multicentric study. Then, SCBC procedures are different with particular differences in the administration of drugs (continuous intravenous or bolus injection). However identical diagnostic performances have been demonstrated on suspected 


\section{Conclusion}

2 We demonstrated that SCBC appears to be safe. The risk of complication is 3 considerably increased in patients with a familial history of complicated SCBC and in very

4 young patients. Specific ECG markers should also be used to detect patients at higher risk.

5 Notably, a fast enlargement during the test may sensitize the physician about the risk of 6 complication.

Although conduction disturbance appears efficient to predict a positive test, QRS

8 enlargement is not significantly related to complications in our study. It should not be used to

9 prematurely stop the test unless leading to false negative results. However, 
1 Acknowledgements: We would like to first thank families who agreed to be involved in this

2 study. We are also grateful to the "Centre de référence des maladies rythmiques héréditaires"

3 and to the molecular diagnosis team of the university hospital of Nantes, for their help in this

4 study.

5

$6 \quad$ Funding source: This research did not receive any specific grant from funding agencies in

7 the public, commercial, or not-for-profit sectors.

8

9 Conflicts of Interest statement: The authors have no conflicts of interest nor financial 10 relationships relevant to this article to disclose. 
References

1. Brugada P, Brugada J: Right bundle branch block, persistent ST segment elevation and sudden cardiac death: a distinct clinical and electrocardiographic syndrome. A multicenter report. J Am Coll Cardiol 1992; 20:1391-1396.

2. Priori SG, Wilde AA, Horie M, et al.: HRS/EHRA/APHRS expert consensus statement on the diagnosis and management of patients with inherited primary arrhythmia syndromes: document endorsed by HRS, EHRA, and APHRS in May 2013 and by ACCF, AHA, PACES, and AEPC in June 2013. Heart

3. Gallagher MM, Forleo GB, Behr ER, Magliano G, De Luca L, Morgia V, De Liberato F, Romeo F: Prevalence and significance of Brugada-type ECG in

4. Makimoto H, Nakagawa E, Takaki H, Yamada Y, Okamura H, Noda T, Satomi K,

5. Keller DI, Rougier J-S, Kucera JP, Benammar N, Fressart V, Guicheney P, Madle A, Fromer M, Schläpfer J, Abriel H: Brugada syndrome and fever: genetic and molecular characterization of patients carrying SCN5A mutations. Cardiovasc Res 2005; 67:510-519. 
1 6. Antzelevitch C, Brugada $P$, Borggrefe $M$, et al.: Brugada syndrome: report of the second consensus conference: endorsed by the Heart Rhythm Society and the European Heart Rhythm Association. Circulation 2005; 111:659-670.

7. Batchvarov VN, Govindan M, Camm AJ, Behr ER: Significance of QRS prolongation during diagnostic ajmaline test in patients with suspected Brugada syndrome. Heart Rhythm Off J Heart Rhythm Soc 2009; 6:625-631.

8. Dobbels B, De Cleen D, Ector J: Ventricular arrhythmia during ajmaline challenge for the Brugada syndrome. Eur Eur Pacing Arrhythm Card Electrophysiol J Work Groups Card Pacing Arrhythm Card Cell Electrophysiol Eur Soc Cardiol 2016; .

9. Rolf S, Bruns H-J, Wichter T, Kirchhof P, Ribbing M, Wasmer K, Paul M, Breithardt G, Haverkamp W, Eckardt L: The ajmaline challenge in Brugada syndrome: diagnostic impact, safety, and recommended protocol. Eur Heart J 2003; 24:1104-1112.

10. Wolpert C, Echternach C, Veltmann C, Antzelevitch C, Thomas GP, Spehl S, Streitner F, Kuschyk J, Schimpf R, Haase KK, Borggrefe M: Intravenous drug challenge using flecainide and ajmaline in patients with Brugada syndrome. Heart Rhythm Off J Heart Rhythm Soc 2005; 2:254-260.

11. Veltmann C, Wolpert C, Sacher F, Mabo P, Schimpf R, Streitner F, Brade J, Kyndt F, Kuschyk J, Le Marec H, Borggrefe M, Probst V: Response to intravenous ajmaline: a retrospective analysis of 677 ajmaline challenges. Eur Eur Pacing Arrhythm Card Electrophysiol J Work Groups Card Pacing Arrhythm Card Cell Electrophysiol Eur Soc Cardiol 2009; 11:1345-1352. 
12. Potet F, Mabo P, Le Coq G, Probst V, Schott J-J, Airaud F, Guihard G, Daubert JC, Escande D, Le Marec H: Novel brugada SCN5A mutation leading to ST segment elevation in the inferior or the right precordial leads. J Cardiovasc Electrophysiol 2003; 14:200-203.

13. Kapplinger JD, Giudicessi JR, Ye D, Tester DJ, Callis TE, Valdivia CR, Makielski JC, Wilde AA, Ackerman MJ: Enhanced Classification of Brugada SyndromeAssociated and Long-QT Syndrome-Associated Genetic Variants in the SCN5AEncoded Na(v)1.5 Cardiac Sodium Channel. Circ Cardiovasc Genet 2015; 8:582-595.

14. Syam N, Chatel S, Ozhathil LC, Sottas V, Rougier J-S, Baruteau A, Baron E, Amarouch M-Y, Daumy X, Probst V, Schott J-J, Abriel H: Variants of Transient Receptor Potential Melastatin Member 4 in Childhood Atrioventricular Block. J Am Heart Assoc 2016; 5.

15. Nishizaki M, Sakurada H, Yamawake N, Ueda-Tatsumoto A, Hiraoka M: Low risk for arrhythmic events in asymptomatic patients with drug-induced type 1 ECG. Do patients with drug-induced Brugada type ECG have poor prognosis? (Con). Circ J Off J Jpn Circ Soc 2010; 74:2464-2473.

16. Gourraud J-B, Barc J, Thollet A, Le Marec H, Probst V: Brugada syndrome: Diagnosis, risk stratification and management. Arch Cardiovasc Dis 2017; 110:188-195.

17. Conte G, Dewals W, Sieira J, et al.: Drug-induced brugada syndrome in children: clinical features, device-based management, and long-term followup. J Am Coll Cardiol 2014; 63:2272-2279. 
1 18. Probst V, Kyndt F, Potet F, Trochu J-N, Mialet G, Demolombe S, Schott J-J, Baró

19. Andorin A, Behr ER, Denjoy I, et al.: The Impact of Clinical and Genetic Findings on The Management of Young Brugada Syndrome Patients. Heart Rhythm Off J Heart Rhythm Soc 2016; .

20. Probst V, Denjoy I, Meregalli PG, et al.: Clinical aspects and prognosis of Brugada syndrome in children. Circulation 2007; 115:2042-2048.

21. Conte G, Sieira J, Sarkozy A, et al.: Life-threatening ventricular arrhythmias during ajmaline challenge in patients with Brugada syndrome: incidence, clinical features, and prognosis. Heart Rhythm 2013; 10:1869-1874.

22. Calò L, Giustetto C, Martino A, et al.: A New Electrocardiographic Marker of Sudden Death in Brugada Syndrome: The S-Wave in Lead I. J Am Coll Cardiol 2016; 67:1427-1440.

23. Pinar Bermúdez E, García-Alberola A, Martínez Sánchez J, Sánchez Muñoz JJ, Valdés Chávarri M: Spontaneous sustained monomorphic ventricular tachycardia after administration of ajmaline in a patient with Brugada syndrome. Pacing Clin Electrophysiol PACE 2000; 23:407-409.

24. Shimizu W, Antzelevitch C, Suyama K, Kurita T, Taguchi A, Aihara N, Takaki H, Sunagawa K, Kamakura S: Effect of sodium channel blockers on ST segment, 
QRS duration, and corrected QT interval in patients with Brugada syndrome. J Cardiovasc Electrophysiol 2000; 11:1320-1329.

25. Meregalli PG, Ruijter JM, Hofman N, Bezzina CR, Wilde AAM, Tan HL: Diagnostic value of flecainide testing in unmasking SCN5A-related Brugada syndrome. J Cardiovasc Electrophysiol 2006; 17:857-864.

26. Wilde AAM, Postema PG: Risk Stratification in Brugada Syndrome; The “Impossible" Made Possible? $\square$. J Am Coll Cardiol 2016; 67:1441-1443.

27. Coronel R, Casini S, Koopmann TT, et al.: Right ventricular fibrosis and conduction delay in a patient with clinical signs of Brugada syndrome: a combined electrophysiological, genetic, histopathologic, and computational study. Circulation 2005; 112:2769-2777.

28. Postema PG, van Dessel PFHM, Kors JA, Linnenbank AC, van Herpen G, Ritsema van Eck HJ, van Geloven N, de Bakker JMT, Wilde AAM, Tan HL: Local depolarization abnormalities are the dominant pathophysiologic mechanism for type 1 electrocardiogram in brugada syndrome a study of electrocardiograms, vectorcardiograms, and body surface potential maps during ajmaline provocation. J Am Coll Cardiol 2010; 55:789-797.

29. Arnalsteen-Dassonvalle E, Hermida J-S, Kubala M, Six I, Quenum S, Leborgne L, Jarry G: Ajmaline challenge for the diagnosis of Brugada syndrome: which protocol? Arch Cardiovasc Dis 2010; 103:570-578. 
$1 \quad$ Tables

2

3 Table 1: description of the population

4 SCBC: sodium channel blocker challenge

5 SCD: sudden cardiac death

\begin{tabular}{|c|c|c|c|c|c|}
\hline & \multicolumn{2}{|c|}{ Groups } & \multirow[t]{2}{*}{ Total } & \multirow[t]{2}{*}{ p value } \\
\hline & & Positive SCBC & Negative SCBC & & \\
\hline \multicolumn{2}{|l|}{ Total } & $337(50 \%)$ & $335(50 \%)$ & 672 & \\
\hline \multicolumn{2}{|l|}{ Age (years) } & $41+/-16$ & $36+/-17$ & $40+/-17$ & 0.004 \\
\hline \multicolumn{2}{|c|}{ Sex: male (n (\%)) } & $154(46 \%)$ & $174(52 \%)$ & $328(49 \%)$ & NS \\
\hline \multicolumn{2}{|c|}{ Syncope (n (\%)) } & $82(9 \%)$ & $18(2 \%)$ & $11(1,6 \%)$ & NS \\
\hline \multicolumn{2}{|c|}{ Familial history of SCD (n (\%)) } & $142(42 \%)$ & $123(37 \%)$ & $265(39 \%)$ & NS \\
\hline \multicolumn{2}{|c|}{ number of affected relatives (median) } & 4 & ( & 4 & NS \\
\hline \multicolumn{2}{|c|}{ SCN5A mutation in family $(\mathrm{n}, \%)$} & $93(79 \%)$ & $27(28 \%)$ & $120(45 \%)$ & $<0.001$ \\
\hline \multirow{2}{*}{ Molecule used } & Ajmaline & $272(81 \%)$ & $225(67 \%)$ & $497(74 \%)$ & \multirow{2}{*}{$<0.001$} \\
\hline & \begin{tabular}{|l} 
Flecainide \\
\end{tabular} & $65(19 \%)$ & $110(33 \%)$ & $175(26 \%)$ & \\
\hline
\end{tabular}

6

7 
1 Table 2: ECG parameters according to sodium channel blocker challenge results

2 SCBC+: positive sodium channel blocker challenge

3 SCBC-: negative sodium channel blocker challenge

4

\begin{tabular}{|c|c|c|c|c|c|c|}
\hline & \multicolumn{3}{|c|}{ Baseline } & \multicolumn{3}{|c|}{ End of the test } \\
\hline & $\mathrm{SCBC}+(n=326)$ & SCBC $-(n=328)$ & $\mathrm{p}$ value & $\mathrm{SCBC}+(\mathrm{n}=328)$ & SCBC $-(n=329)$ & $\mathrm{p}$ value \\
\hline \multicolumn{7}{|l|}{$\overline{D I I}(\mathrm{~ms})$} \\
\hline QRS & $92 \pm 19$ & $82 \pm 16$ & $<0.0001$ & $123 \pm 24$ & $101 \pm 20$ & $<0.0001$ \\
\hline \multicolumn{7}{|l|}{$V 1(m s)$} \\
\hline$\overline{\mathbf{P}}$ & $68 \pm 19$ & $62 \pm 17$ & $<0.0001$ & $83 \pm 22$ & $72 \pm 19$ & $<0.0001$ \\
\hline $\mathbf{P Q}$ & $156 \pm 31$ & $146 \pm 27$ & $<0.0001$ & $201 \pm 40$ & $178 \pm 35$ & $<0.0001$ \\
\hline QRS & $94 \pm 17$ & $91 \pm 15$ & 0.06 & $112 \pm 26$ & $103 \pm 20$ & $<0.0001$ \\
\hline QT peak & $299 \pm 34$ & $299 \pm 34$ & 0.99 & $317 \pm 37$ & $298 \pm 36$ & $<0.0001$ \\
\hline$\overline{\text { QTe }}$ & $407 \pm 39$ & $394 \pm 36$ & $<0.0001$ & $468 \pm 51$ & $420 \pm 38$ & $<0.0001$ \\
\hline TPE & $71 \pm 25$ & $68 \pm 17$ & 0.0005 & $90 \pm 27$ & $75 \pm 22$ & $<0.0001$ \\
\hline \multicolumn{7}{|c|}{ S duration (ms) } \\
\hline DII & $35 \pm 24$ & $23 \pm 21$ & $<0.0001$ & $58 \pm 27$ & $35 \pm 24$ & $<0.0001$ \\
\hline DIII & $33 \pm 28$ & $20 \pm 24$ & $<0.0001$ & $47 \pm 36$ & $28 \pm 28$ & $<0.0001$ \\
\hline V5 & $42 \pm 19$ & $28 \pm 18$ & $<0.0001$ & $67 \pm 21$ & $50 \pm 16$ & $<0.0001$ \\
\hline \multicolumn{7}{|c|}{$R$ duration (ms) } \\
\hline aVR & $32 \pm 22$ & $25 \pm 20$ & $<0.0001$ & $52 \pm 25$ & $35 \pm 22$ & $<0.0001$ \\
\hline \multicolumn{7}{|c|}{ S amplitude (mV) } \\
\hline DII & $1.72 \pm 1.7$ & $1.2 \pm 1.5$ & $<0.0001$ & $3 \pm 2.2$ & $2.2 \pm 2.8$ & $<0.0001$ \\
\hline DIII & $2 \pm 2.8$ & $1.3 \pm 2.5$ & $<0.0001$ & $2.5 \pm 2.9$ & $1.8 \pm 2.6$ & $<0.0001$ \\
\hline V5 & $3.5 \pm 3$ & $2.6 \pm 2.9$ & $<0.0001$ & $7 \pm 4.8$ & $5 \pm 3.5$ & 0.0003 \\
\hline \multicolumn{7}{|c|}{$R$ amplitude ( $\mathrm{mV}$ ) } \\
\hline$\overline{\text { aVR }}$ & $1.5 \pm 2.1$ & $1.1 \pm 1.78$ & $<0.0001$ & $2.4 \pm 1.5$ & $1.9 \pm 2.6$ & $<0.0001$ \\
\hline
\end{tabular}




\section{$1 \quad$ Figures legend}

2

$3 \quad$ Figure 1: Example of a positive SCBC.

4 The test (ajmaline $1 \mathrm{mg} / \mathrm{kg}$ over $10 \mathrm{~min}$ ) was performed in an asymptomatic 18 yo woman

5 after the identification of a symptomatic BrS in her father.

6 Please note the S wave in DII and DIII on baseline ECG and the QRS fragmentation in 7 precordial leads.

8 Measurement performed in 3 consecutive beats reveal a significant increased in the PR

9 interval (from $268 \mathrm{~ms}$ to $304 \mathrm{~ms}$ ), the QRS interval (from $81 \mathrm{~ms}$ to $143 \mathrm{~ms}$ ) and the QT

10 interval (from $381 \mathrm{~ms}$ to $420 \mathrm{~ms}$ ) during the test. All ECG was performed with a $25 \mathrm{~mm} / \mathrm{s}$

11 speed and a $10 \mathrm{~mm} / \mathrm{mV}$ amplitude. No complication occurred during the test.

13 Figure 2: Proportion of positive and complicated SCBC according to QRS enlargement

14 Percentage of positive SCBC according to QRS enlargement is represented in blue.

15 Percentage of complicated SCBC according to QRS enlargement is represented in red. 
Baseline ECG
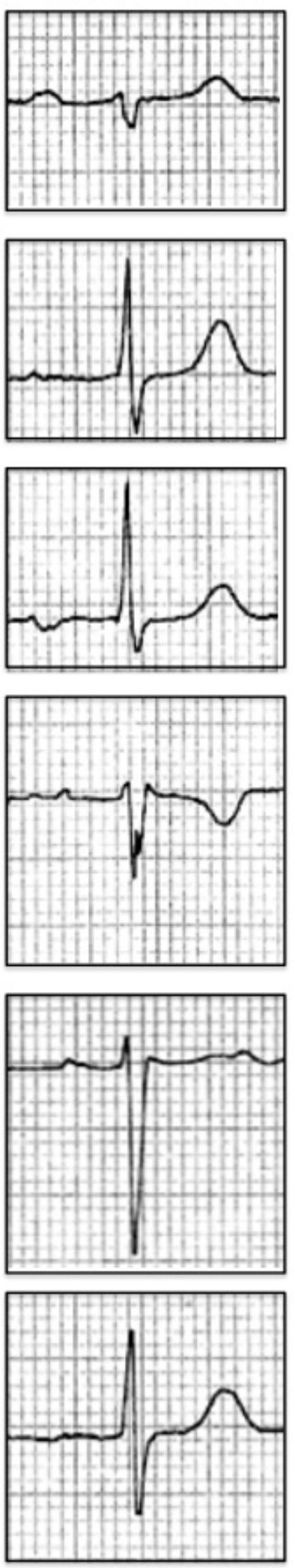

SCBC
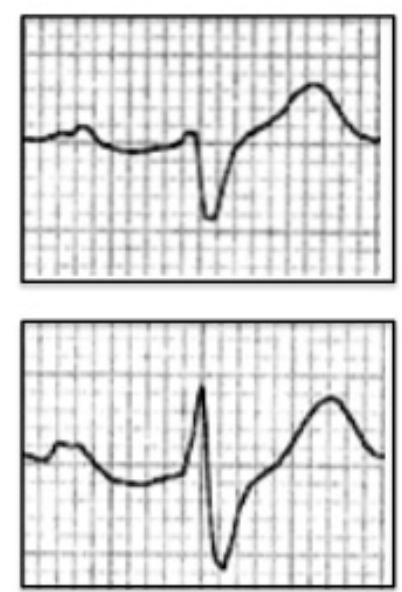

V1
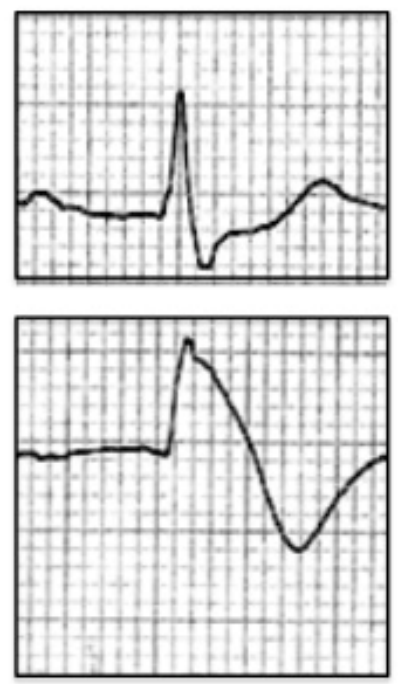

V2

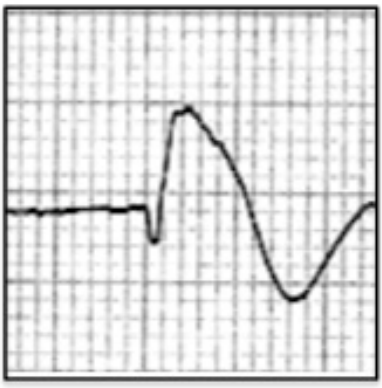

V3

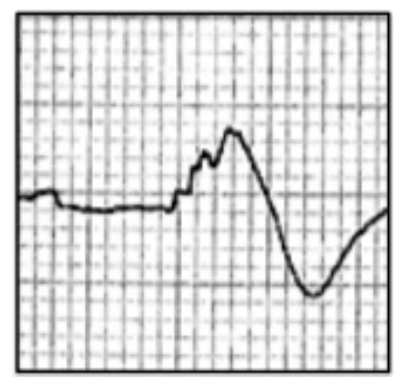




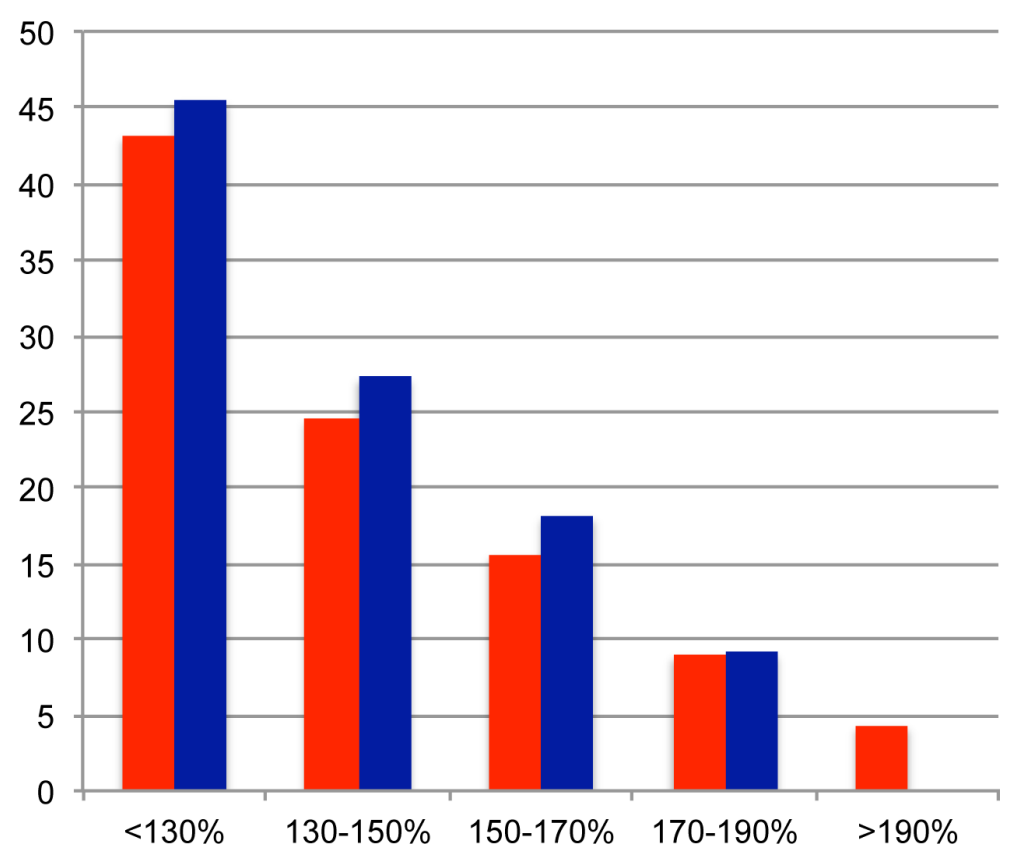

- Positive SCBC ( $n=301)$

- Complicated SCBC ( $n=11)$ 